\title{
Effects of various grated sago sizes, steeping periods and trunk sections on sago starch recovery (Metroxylon spp.)
}

\author{
${ }^{1,2}$ Wan Mohd Fariz, W.A., ${ }^{1 *}$ Rosnah, S., ${ }^{1}$ Mohd Zuhir, M.N., ${ }^{2}$ Azman, S. and ${ }^{3}$ Noramina, H. \\ ${ }^{1}$ Faculty of Engineering, Universiti Putra Malaysia, 43400 UPM Serdang, Selangor, Malaysia \\ ${ }^{2}$ Engineering Research Center, MARDI Headquarters, 43400 Persiaran MARDI-UPM, Selangor, Malaysia \\ ${ }^{3}$ CRAUN Research Sdn Bhd, 93050 Kuching, Sarawak, Malaysia
}

\begin{abstract}
Article history:
Received: 4 February 2020

Received in revised form: 6 March 2020

Accepted: 8 March 2020

Available Online: 30 March 2020
\end{abstract}

\section{Keywords:}

Sago palm,

Starch,

Grated sago size,

Steeping,

Extraction

\section{DOI:}

https://doi.org/10.26656/fr.2017.4(4).053

\begin{abstract}
The sago palm stored a native starch between the trunk fiber gap. The trunk needed to be crushed into a fine size using a mechanical system. In general, the grated sago size affects the extraction efficiency, which depends on sago starch that dissolved in water during an extraction process. Therefore, the aim of this study was to determine the effect of grated sago sizes on starch recovery at different steeping periods and trunk sections. The sago trunks used were selected at three palm section (Top, Middle and Bottom). After the grating process using Sago Grater, the grated sago was dried and sieved at different sizes $(2.80 \mathrm{~mm}, 2.00 \mathrm{~mm}, 1.00 \mathrm{~mm}, 0.85 \mathrm{~mm}, 0.45 \mathrm{~mm}$ and $0.30 \mathrm{~mm})$. Furthermore, the grated sago with different sizes was steeped in sodium metabisulphite $\left(\mathrm{Na}_{2} \mathrm{~S}_{2} \mathrm{O}_{5}\right)$ at different periods (5 mins, $24 \mathrm{hrs}, 48 \mathrm{hrs}$ and $72 \mathrm{hrs}$ ) for starch extraction. The results showed that the independent variables of grated size most significantly affected starch recovery $(\mathrm{P}<0.05)$. A substantial amount of starch could be recovered from grated sago by reducing the grated size at $X<0.30 \mathrm{~mm}$ which was up to $58 \%$ of the extraction efficiency. The increment of the steeping period from 5 mins up to $24 \mathrm{hrs}$ increased the starch recovery; however, a longer steeping period showed an insignificant difference $(\mathrm{P}>0.05)$. Additionally, the trunk selection also affects the starch recovery, however, it does not influence the extraction efficiency.
\end{abstract}

\section{Introduction}

In Malaysia, more than $90.0 \%$ of sago planting areas are in Sarawak state since most of the state areas were covered by wetland that is very suitable for sago cultivation and it has become one of the important industries. Nowadays, Malaysia has become the third main sago producer in the world (Naim et al., 2016). Previously, the Malaysia Department of Statistics (2005) reported that Malaysia exported 45,300 metric tons weight of sago starch, approximately RM 40.40 million. In 2017, there was an increment in the annual sago production to 212,447 metric tons of sago starch (DOA, 2017), estimated to be equivalent to RM 189.47 million. This indicates that the increase of production was due to the increase of current demand which is in line with the growth of starch utilization in manufacturing industry applications. Furthermore, even though the source of starch from sago was optional, sago starch is advantageous because it contains four times greater starch content than rice (Yamamoto, 2014). Starch is an important raw material for the processing operations in the manufacturing industries such as agro industries, biopesticides, bio-ethanols, cosmetics, and pharmaceutical industry (Bintoro, 2011). In addition, its microbial resistant ability is advantageous as additional material in the production of biodegradable material in packaging technology. However, it has low durability in a single form. Therefore, it is essential to blend it with additional material to produce long-lasting and durable composite material (Yajie et al., 2020).

Nowadays, in the sago palm industry processing method, both in traditional or modern handling, the sago processing procedures remain the same. Briefly, it involves peeling, size reduction, grating, extraction and sedimentation. Before the processing begins, usually the trunk barks need to be removed or peeled manually using axes and then grated using sharp nails. During the grating process, water is added continuously to the grated trunks in order to transfer them to a rotating mesh screener that functions as an extractor. The extracted water solution from the grated trunk contains starch that is channeled to the sedimentation tank. After two hours, 
the starch will settle down at the bottom of the tank and the excess water on the top layer inside the tank is removed (Yamamoto, 2014; Darma et al., 2017). According to Abd Aziz (2002), 65.7\% of the grated residue after the extraction process contained starch. Linggang et al. (2012) also stated that about $58 \%$ of the residue was recorded still contained starch. Since the residue is mostly dumped into the river, using the total loss rate (assuming about 65.7\%), it was estimated about 406,932 metric tons of sago starch is wasted based on the total sago production reported by DOA (2017). The losses occur due to the inefficiency of the extraction process. One of the factors that influence the extraction efficiency is the proportion of the sago trunk structure that ruptured which is producing various of grated sago size (Tay et al., 2013). The native sago starch extraction is different from roots and cereals as it is more complicated. The mean diameter of native sago starch granule was $29.4 \mu \mathrm{m}$ (Kaur et al., 2011) and stored in the parenchyma cells of the coarse vascular bundles that contain a high amount of lignin. The lignins had important roles in the lodging resistance ( $\mathrm{Hu}$ et al., 2017). Furthermore, the native starch granules also fill up the empty spaces between the lignins and bond the lignins together. As a result, the separation of sago native starch from the trunk is a challenge. Therefore, the size of the grated sago trunk plays an important factor to increase extraction efficiency and high recovery.

The purpose of this study was to determine the effect of various grated sago sizes on the starch recovery during the extraction from sago palm at different steeping periods. Furthermore, this study also evaluated the effect of sago trunk at different sections (Top, Middle and Bottom) to the grated size and starch yield.

\section{Materials and methods}

\subsection{Raw material selection}

The selection of sago palm for the assessment is based on the tree's maturity stage, which contains the maximum starch content. As reported by Jong (1995a), the stage was between growing and flowering. The sago palms were harvested at Labu in the State of Negeri Sembilan. After harvesting, the sago palm trunks were categorized into three sections: Top (T: $1 \mathrm{~m}$ from frond base), Middle (M: between $5 \mathrm{~m}$ to $6 \mathrm{~m}$ from the ground surface) and Bottom (B: up to 1 meter from the ground surface) as shown in Figure 1. Each identified section of sago trunk was cut into $50 \mathrm{~cm}$ length. The trunk barks were peeled off using handheld chainsaws (OG6816, Ogawa, Japan) and cut into square blocks of $10 \mathrm{~cm} \times 10$ $\mathrm{cm} \times 10 \mathrm{~cm}$. The lignin orientation direction (the sago palm lignin orientation was parallel to the trunk's vertical axis) was marked as an arrow.

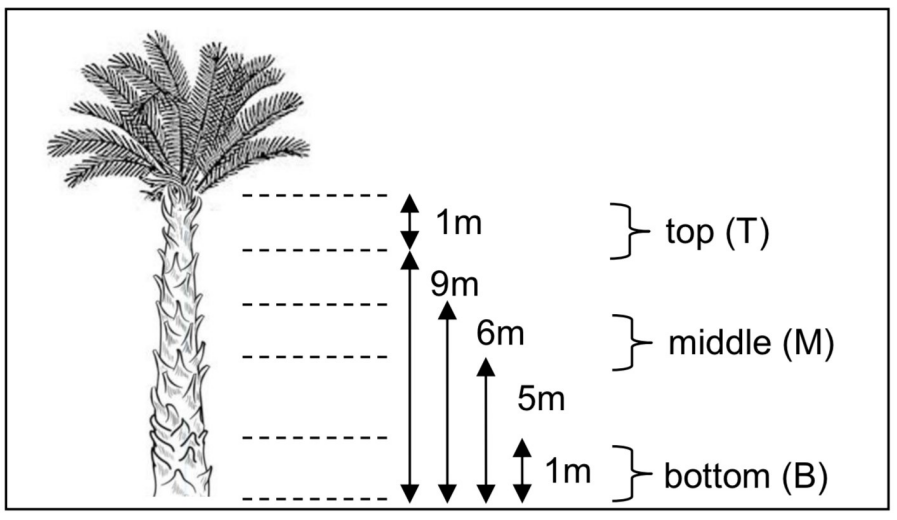

Figure 1. Sago palm trees section (Wan Mohd Fariz et al., 2018)

\subsection{Raw material grating process}

The purpose of the grating process was to break the trunk structures into a finer size in order to remove or loosen the native starch from the trunk structures. The grating process of sago trunk block was conducted using a Sago Grater with the grating direction being parallel to the vertical axis of the sago trunk lignin orientation. According to the report by Wan Mohd Fariz et al. (2018), grating at the parallel direction to the vertical axis of sago trunk lignin orientation produced finer grated trunk and higher starch yield recovery compared to the perpendicular direction. Therefore, the sago blocks were placed on the feeding platform in a position where the sago trunk lignin orientation (arrow mark) pointed to the grater blade direction as previously done by Wan Mohd Fariz et al. (2018). The grating process was carried out and the repeated six times for each sago block section. The grated sago trunk blocks from each section ( $T, M$ and $B$ ) were collected separately.

\subsection{Assessment of grated sago size distribution}

The sieving process was conducted to separate the grated sago particles according to size. First, the grated sago was dried at $68^{\circ} \mathrm{C}$ (Jong,1995a) using an air-drying oven (FAC-100, Protech, Malaysia). The drying process was stopped when the moisture content (MC) value showed a constant value for three consecutive readings taken at every half an hour. After drying, $100 \mathrm{~g}$ of dried grated sago was sieved using a sieve shaker (Endecott, United Kingdom). At every 10 mins interval of the sieving process, the total weight of the sieve and content were measured. The sieving process was stopped when three consecutive readings of the total weight showed a constant value (ASTM, 2001). Referring to the grated sago distribution assessment by Wan Mohd Fariz et al. (2018), the selected grade of sieved sizes used were 2.80 $\mathrm{mm}, 2.00 \mathrm{~mm}, 1.00 \mathrm{~mm}, 0.85 \mathrm{~mm}, 0.45 \mathrm{~mm}$ and 0.30 $\mathrm{mm}$. The sieving process was repeated six times to get an average $(\mu)$ and standard deviation (SD: \pm ). The weight for each sieve product according to the grade of sieved 
sizes was recorded. Finally, the Weight Percentage Ratios (WPR) for each sieve product were calculated (equation 1). Additionally, the $\mathrm{MC}$ of the grated sago before and after drying were measured using digital measuring devices (HE53 230V, Mettler Toledo, USA).

Weight Percentage Ratio (WPR) $\%=\frac{\text { Weight of the sieved products }}{\text { Total weight of grated sago sample }} \times 100 \%$

\subsection{Starch extraction using steeping method}

The steeping method used water as solvent in order to extract the native starch. Dried grated material (sago trunk) of $2 \mathrm{~g}$ according to the grade sizes $(2.80 \mathrm{~mm}, 2.00$ $\mathrm{mm}, 1.00 \mathrm{~mm}, 0.85 \mathrm{~mm}, 0.45 \mathrm{~mm}, 0.30 \mathrm{~mm}$ and $<0.30$ $\mathrm{mm}$ ) were steeped in $0.2 \%$ sodium metabisulphite $\left(\mathrm{Na}_{2} \mathrm{~S}_{2} \mathrm{O}_{5}\right)$ (Tay et al., 2013) which was dissolved in water $\left(\mathrm{H}_{2} \mathrm{O}\right)$ at room temperature as shown in Figure 2. The steeping period was set at $5 \mathrm{mins}, 24 \mathrm{hrs}, 48 \mathrm{hrs}$ and $72 \mathrm{hrs}$. The ratio of dried grated material to the steeping solution was 1:6 (w/w). The extracted liquids were centrifuged at $2000 \mathrm{rpm}$ for $10 \mathrm{mins}$ and analyzed to determine the value of starch content using VIS spectrophotometer (Lambda 35, Perkin Elmer, USA) at $650 \mathrm{~nm}$ wavelength. An iodine solution was added into the solution as a starch indicator (Tay et al., 2013). The experiments were repeated six times. The starch recovery percentage at different grated sizes was calculated (equation 2).

Starch percentage recovery $(\%)=\frac{\text { Dry Starch }(\mathrm{g})}{\text { Wet grated sago weight }(\mathrm{g})} \times 100 \%$

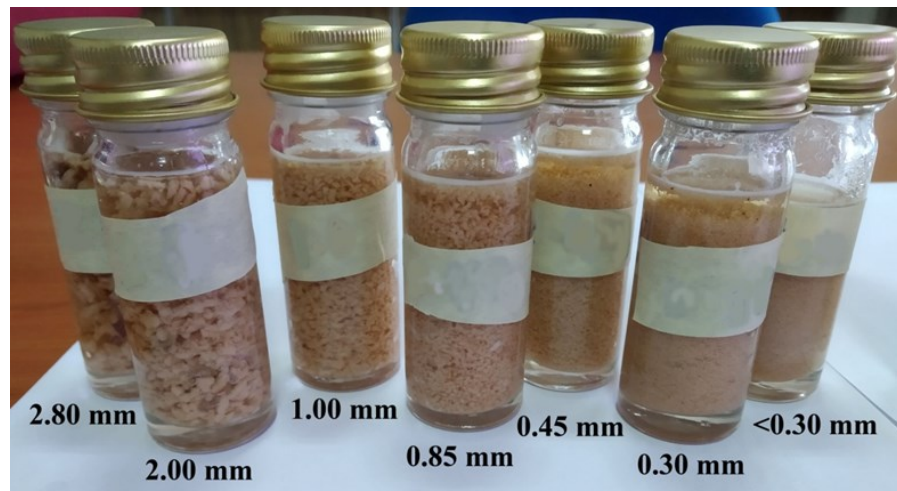

Figure 2. Grated sago $(2.80 \mathrm{~mm}, 2.00 \mathrm{~mm}, 1.00 \mathrm{~mm}, 0.85$ $\mathrm{mm}, 0.45 \mathrm{~mm} 0.30 \mathrm{~mm}$ and $<0.30 \mathrm{~mm}$ ) was soaking in $0.2 \%$ of $\mathrm{Na}_{2} \mathrm{~S}_{2} \mathrm{O}_{5}$ and dissolved in $\mathrm{H}_{2} \mathrm{O}$.

\subsection{Chemical composition and extraction efficiency}

A dry grated sago trunk (sample: T, M and B) was subjected to chemical determination for total starch according to AACC 76-13.01 (2000) method by using a kit by Megazyme International Ireland Ltd (AACC, 2000). The experiments were repeated six times. In addition, the extraction steeping method efficiency was calculated using equation 3 .

Extraction $\frac{\text { Starch extraction using chemical composition }}{\times 100 \%}$

\subsection{Data analysis}

The statistical data and variance analysis (ANOVA) were analyzed using IBM SPSS Statistics 25.0 software to test the main effects of independent and interaction parameters. The significant difference was measured at a confidence level of $95 \%(\mathrm{P}<0.05)$.

\section{Results and discussion}

3.1 Grated sago size distribution assessment produced by grating machine

The determination of moisture content (MC) on the material to be grated was important because it affects the trunk toughness which in turn influenced the grating capability. As the MC of wood increased, the ductility eventually increased. Furthermore, higher MC increased the specific toughness (Oyedeji et al., 2017). Figure 3 shows the $\mathrm{MC}$ of sago trunk according to sections ( $\mathrm{T}, \mathrm{M}$ and $\mathrm{B})$. The average $\mathrm{MC}$ between the sago trunks sections ( $\mathrm{T}, \mathrm{M}, \mathrm{B})$ showed an insignificant difference in values $(\mathrm{p}>0.05)$, ranging between 51.23 to $62.34 \%$ $(\mu=59.00 \pm 4.21)$. Therefore, the MC factor may not affect the trunk toughness at the different palm trunk sections (T, M, B) for this study. In addition, according to the report by Yamada et al. (2010), the MC of sago trunk was lower than that oil palm trunk which was $78 \%, 75 \%$ and $67 \%(\mu=74.00 \pm 4.58 \%)$ with a percentage difference of $20.27 \%(\mathrm{P}<0.05)$. Furthermore, the sago trunk (palm type) MC is extremely high compared to ordinary wood timber which normally ranges between $40 \%$ to $50 \%$ as stated by Yamada et al. (2010).

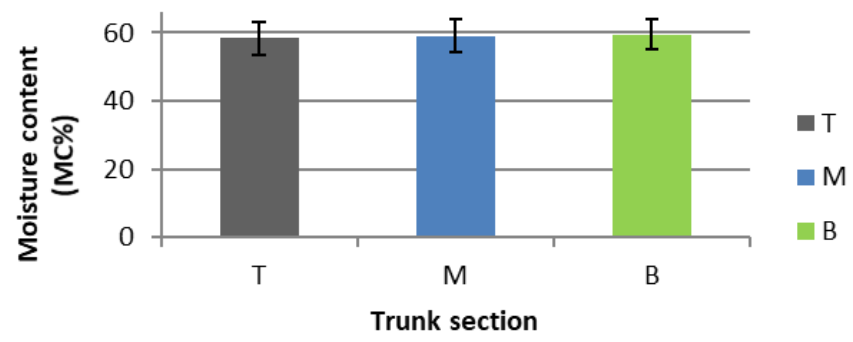

Figure 3. The moisture content (MC\%) of sago trunk at Top $(\mathrm{T})$, Middle (M) and Bottom (B) sections. Error bars were expressed as mean $\pm \mathrm{SD} ; \mathrm{n}=12$

Determination of grated sago distribution was conducted according to sizes: $\mathrm{X}<0.30 \mathrm{~mm}, 0.30 \leq \mathrm{X}<0.45$ $\mathrm{mm}, 0.45 \leq \mathrm{X}<0.85 \mathrm{~mm}, 0.85 \leq \mathrm{X}<1.00 \mathrm{~mm}, 1.00 \leq \mathrm{X}<2.00$ $\mathrm{mm}, 2.00 \leq X<2.80 \mathrm{~mm}$ and $X \geq 2.80 \mathrm{~mm}$, where $X$ refers to the grated sago size range. In order to perform the sieving process, the grated sago needed to be dried as high MC affected the efficiency of the sieving process, causing the material to clump together during the sieving process. The results showed that the average MC of dried grated sago for each trunk section $(\mathrm{T}, \mathrm{M}, \mathrm{B})$ ranged 
between $5.18 \%$ to $6.11 \%$ with an average of $5.53 \pm 0.44 \%$, which is close to the value reported by Wan Mohd Fariz et al. (2018) (5.15 $\pm 0.37 \% ; \mathrm{p}>0.05)$. Figure 4 shows the WPR of grated sago at different sizes (mm). The error bars referred to the standard deviation $( \pm)$ for each average data of WPR. The mesh sizes of $X<0.30$ $\mathrm{mm}, 0.30 \leq \mathrm{X}<0.45 \mathrm{~mm}, 0.85 \leq \mathrm{X}<1.00 \mathrm{~mm}, 2.00 \leq \mathrm{X}<2.80$ $\mathrm{mm}$ and $\mathrm{X} \geq 2.80 \mathrm{~mm}$ showed that the WPR was less than $12 \%$, while the mesh size of $0.45 \leq \mathrm{X}<0.85 \mathrm{~mm}$ showed that the WPR value ranged between 28 to $32 \%$. The highest WPR was recorded at mesh size of $1.00 \leq \mathrm{X}<2.00$ $\mathrm{mm}$, which ranged between 25 to $35 \%$. Cumulatively, the $\mathrm{X}<1.00 \mathrm{~mm}$ (initial assumption as finer grated sago) showed that the highest total WPR was produced by the top section of the trunk $(61.36 \%)$, followed by the middle and bottom sections at $52.06 \%$ and $51.76 \%$ respectively and a significant difference $(\mathrm{P}<0.05)$ between the trunk sections. This might be due to the different hardness of each trunk sections. Naturally, the upper section of the tree trunk is softer than the bottom. Based on a study, the tree trunk hardness was inversely proportional to the tree height (Matsuoka, 2008.). Furthermore, the grated sago size barplot (Figure 4) showed the similar size distribution when the sago block fiber was grated parallel to the direction of the roller grater teeth during the grating process as reported by Wan Mohd Fariz et al. (2018).

\subsection{Native starch extraction using steeping method according to grated sago size}

Producing finer grated sago is important to increase the starch dissolve percentage during an extraction process (Wan Mohd Fariz et al. 2018). Finally, yet importantly, an increase of pulp particle size resulted in a decrease in the starch extraction efficiency since the pulp has a complex structure (Saengchana, 2015). Therefore, a study was conducted to identify the optimal grated sago size to obtain high extracted native starch weight. Figure 5, 6 and 7 show the native starch weight (MC: $10.33 \pm 0.55 \%$ ) extracted from $2 \mathrm{~g}$ of dried grated sago trunk ( $T, M$ and $B$ section) according to sizes $(X<0.30$, $0.30 \leq \mathrm{X}<0.45 \mathrm{~mm}, 0.45 \leq \mathrm{X}<0.85 \mathrm{~mm}, 0.85 \leq \mathrm{X}<1.00$ $\mathrm{mm}, 1.00 \leq \mathrm{X}<2.00 \mathrm{~mm}, 2.00 \leq \mathrm{X}<2.80 \mathrm{~mm}$ and $\mathrm{X} \geq$ $2.80 \mathrm{~mm}$ ) at different steeping period (5 mins, $24 \mathrm{hrs}, 48$ hrs and $72 \mathrm{hrs}$ ). The grated sago at the size of $\mathrm{X}<0.30$ $\mathrm{mm}$ showed higher extracted native starch weight $(0.71$ $\mathrm{g}, 0.68 \mathrm{~g}, 0.67 \mathrm{~g}$; T, M, B) compared to that of the size of $0.30 \leq \mathrm{X}<0.45 \mathrm{~mm}(0.65 \mathrm{~g}, 0.60 \mathrm{~g}, 0.59 \mathrm{~g} ; \mathrm{T}, \mathrm{M}, \mathrm{B})$ for all sections with a significant difference $(\mathrm{P}<0.05)$. Furthermore, the extracted starch weight at size $0.30 \leq$ $\mathrm{X}<0.45 \mathrm{~mm}$ also showed a significant difference $(\mathrm{P}<0.05)$ compared to that of $0.45 \leq \mathrm{X}<0.85 \mathrm{~mm}$ (up to $0.59 \mathrm{~g}$; all sections) for the top section but with no observed significant difference $(\mathrm{P}>0.05)$ for the middle and bottom. The size from $0.45 \leq \mathrm{X}<0.85 \mathrm{~mm}$ to $1.00 \leq \mathrm{X}<2.00 \mathrm{~mm}$ did not show significant differences $(\mathrm{P}>0.05)$ of extracted starch weight (ranging between 0.55 to $0.59 \mathrm{~g}$ ) between sizes and sections. To further elaborate, at size $1.00 \leq X<2.00 \mathrm{~mm}$ and $2.00 \leq X<2.80$ $\mathrm{mm}$, based on observed showed no significant difference $(\mathrm{P}>0.05)$ of extracted starch weight for $\mathrm{T}$ and $\mathrm{M}$ section but observed otherwise for $\mathrm{B}$ trunk section $(\mathrm{P}<0.05)$. Meanwhile, there was a significant difference $(\mathrm{P}<0.05)$ in extracted starch weight between size $2.00 \leq \mathrm{X}<2.80$ $\mathrm{mm}$ and $X \geq 2.80 \mathrm{~mm}$. Overall, the bar graphs (Figure 5, 6 and 7) show the same distribution pattern of extracted starch weight (g) according to the grated sago size produced by the different sections of sago trunk (T, M and B) at different steeping period. The extracted starch weight showed an inversely proportional pattern to the grated sago size: the larger the grated sago size, the less native starch weight was recorded. The present study is in agreement with Wan Mohd Fariz et al. (2018) in which the finer size of grated sago produced higher starch recovery compared to rougher size. Furthermore, a similar starch extraction study by Tay et al. (2013) stated that the increase of the mesh number (sieve mesh size decreases) showed a significant increase of starch yield due to the larger surface area that allowed more material extraction into the steeping solution. Additionally, Mary Anupama et al. (2010) also showed that smaller particle size has contributed to a larger contact surface area, resulting in an increase of starch yield during extraction.

The statistical analysis data (Table 1) showed that the independent parameters (Trunk Section: TS, Grated Sago Size: GS and Steeping Period: SP) and their interaction parameters (TS*GS, GS*SP and TS*GS*SP) significantly affected $(\mathrm{P}<0.05)$ the extracted starch weight except for the interaction between TS*SP. Furthermore, by comparing the F-values, the effect of GS parameter on the extracted starch weight was the most significant between the independent parameters followed by the TS parameters. Meanwhile, TS*GS interaction had the highest F-values compared to other interactions since both of them had independent parameters with the highest F-values. In addition, GS*SP and $\mathrm{TS} * \mathrm{GS} * \mathrm{SP}$ interactions showed the lower F-values because the interactions between independent parameters were lower.

Although all the independent parameters and some of the interactions showed a significant effect on the extracted starch weight, the effect was very low when compared to the F-values. In other words, it means that there were groups of data that had no significant difference in values. Therefore, Post Hoc Tests were conducted by comparing the values between groups in independent parameters, SP and TS. The data of multiple 


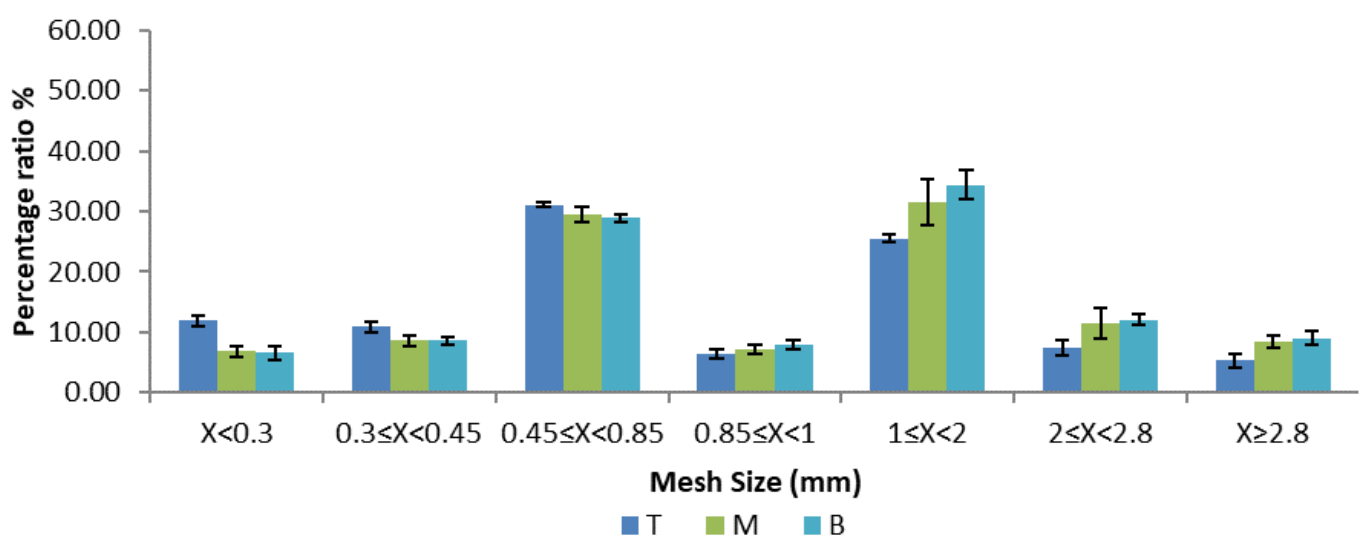

Figure 4. The WPR \% of grated sago at different sieve mesh sizes (mm) according to trunk sections (T, M and B). Error bars were expressed as mean $\pm \mathrm{SD} ; \mathrm{n}=6$.

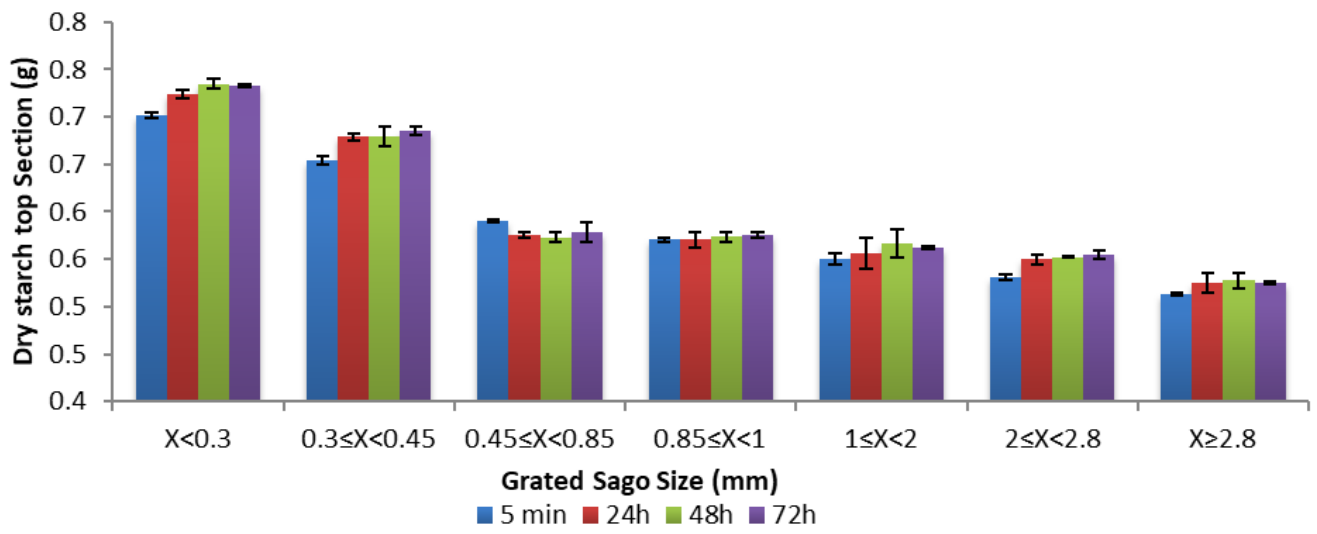

Figure 5. The extracted native starch weight at the top section (T) of sago trunk palm according to grated sago sizes (mm) at different steeping periods ( 5 mins, $24 \mathrm{hrs}, 48 \mathrm{hrs}$ and $72 \mathrm{hrs}$ ). Error bars were expressed as mean $\pm \mathrm{SD} ; \mathrm{n}=6$.

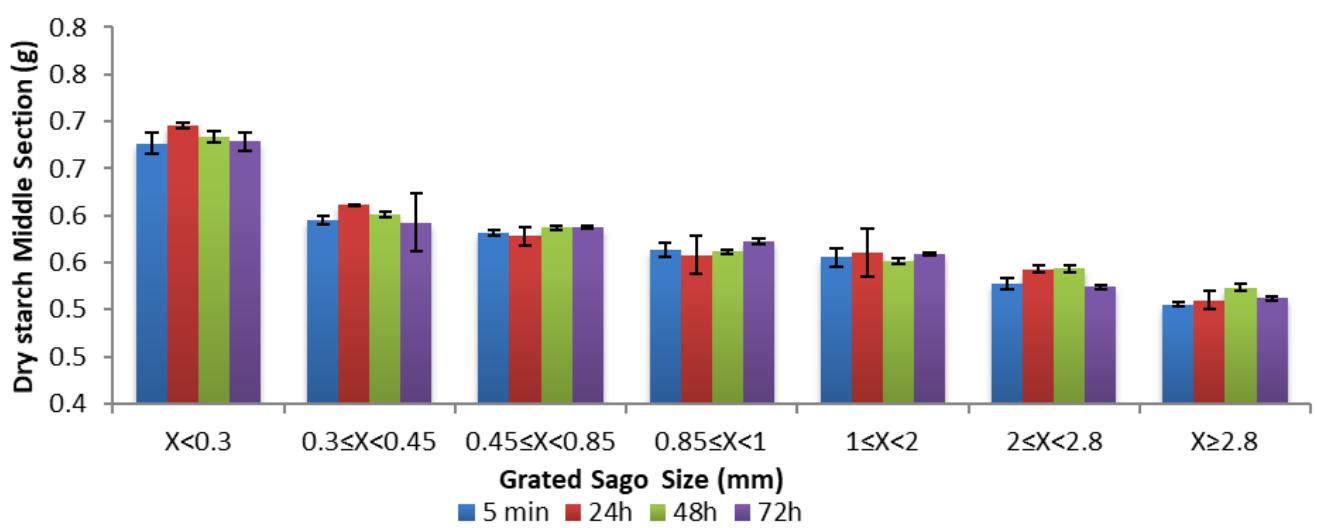

Figure 6. The extracted native starch weight at the middle section (M) of sago trunk palm according to grated sago sizes (mm) at different steeping periods ( $5 \mathrm{mins}, 24 \mathrm{hrs}, 48 \mathrm{hrs}$ and $72 \mathrm{hrs}$ ). Error bars were expressed as mean $\pm \mathrm{SD} ; \mathrm{n}=6$.

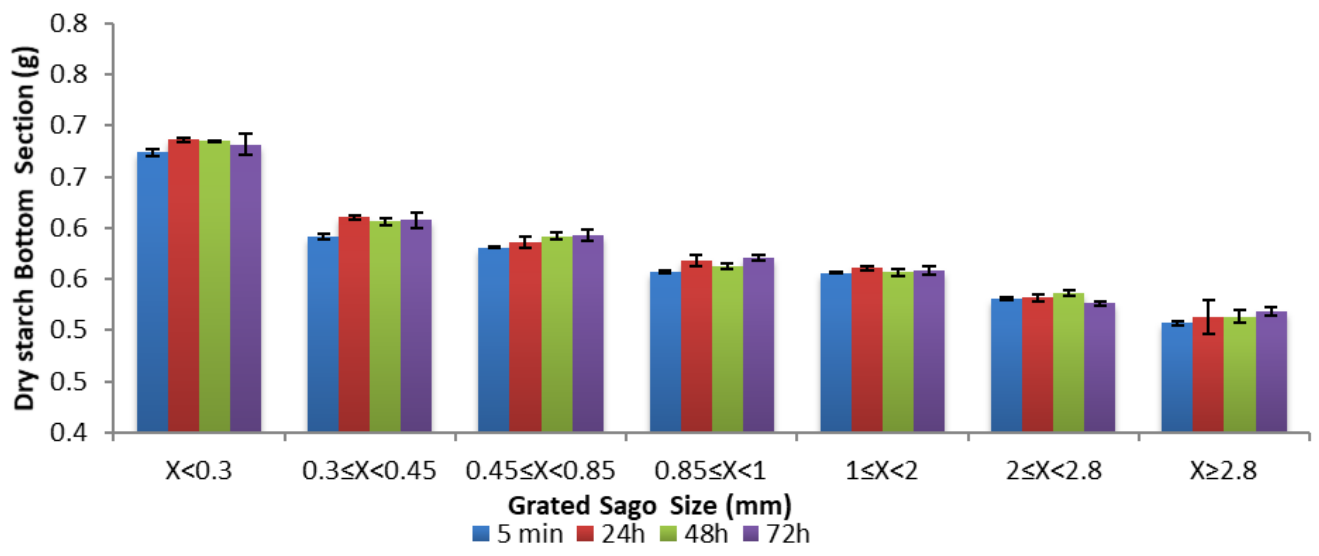

Figure 7. The extracted native starch weight at the bottom section (B) of sago trunk palm according to grated sago sizes (mm) at different steeping periods ( $5 \mathrm{mins}, 24 \mathrm{hrs}, 48 \mathrm{hrs}$ and $72 \mathrm{hrs}$ ). Error bars were expressed as mean $\pm \mathrm{SD} ; \mathrm{n}=6$. 
Table 1. Summary of ANOVA for mean extracted starch weight using different trunk sections, grated sago sizes and steeping periods.

\begin{tabular}{lcccc}
\hline Source & DF & Mean Square & F Value & P Value \\
\hline Trunk Section & 2 & 0.01 & 202.28 & 0 \\
Grated Size & 6 & 0.13 & 2367.96 & 0 \\
Steeping Period & 3 & 0 & 22.33 & 0 \\
Trunk Section * Grated Size & 12 & 0 & 53.21 & 0 \\
Trunk Section * Steeping Period & 6 & 0 & 2.56 & 0.02 \\
Grated Size * Steeping Period & 18 & 0 & 2.88 & 0 \\
Trunk Section * Grated Size * Steeping Period & 36 & 0 & 2 & 0 \\
\hline
\end{tabular}

* Dependent Variable: Extracted starch weight

comparison between the steeping periods showed that only the steeping period of $5 \mathrm{mins}$ had a significant difference $(\mathrm{P}<0.05)$ compared to other steeping periods ( $24 \mathrm{hrs}, 48 \mathrm{hrs}$, and $72 \mathrm{hrs}$ ), showing that there was an increase in extracted starch weight when the steeping period increased from 5 mins to $24 \mathrm{hrs}$. However, further increase of the steeping period from $24 \mathrm{hrs}$ to $48 \mathrm{hrs}$ and $72 \mathrm{hrs}$ did not yield a significant difference in the extracted starch weight. The extraction reached equilibrium beyond $24 \mathrm{hrs}$ because when the steeping period was at $24 \mathrm{hrs}$, most of the loose starch granules in the trunk lignin were released (Tay et al., 2013). Another possibility could due to the increased slurry viscosity since the starch granules were hydrated for a longer period, thereby allowing low release of starch (Mistry et al., 1992).

Meanwhile, the data of multiple comparisons between the trunk sections showed that the Top section had a significant difference $(\mathrm{P}<0.05)$ of extracted starch weight compared to the other sections. However, the Middle and Bottom sections had no significant difference of extracted starch weight due to the uneven distribution of total starch content along the palm trunk as shown in Table 5. The sago starch content distribution depends on the palm tree's maturity as reported by Jong (1995b).

\subsection{Extraction efficiency and starch recovery according to grated size}

The extraction process of native starch normally used water as solvent to extract the starch from fiber while the recovery efficiency depends on the grated sago sizes. In order to determine the extraction efficiency, it is necessary to determine the Total Starch Content (TSC) in the fiber (grated sago) using chemical methods. Table 2 shows the TSC according to the trunk sections and the extraction efficiency according to the grated sizes at different steeping periods. The TSC showed no significant difference between trunk sections $(\mathrm{P}>0.05)$, ranging between 38.98 to $45.40 \%$. Furthermore, the TSC pattern between sections indicates that the palm trees matured at stage nine (flowering stage), corresponding to
12.5 years old as reported by Jong (1995b). The results showed that the sago trunk TSC was higher than an oil palm trunk $(2.12 \%)$ by assuming that the fresh input material was at $\mathrm{MC}=74.00 \pm 4.58 \%$ (Yamada et al., 2010).

Furthermore, the results showed that the highest efficiency of extraction occurred when the steeping periods is 24 hours for grated sago at the size of $X<0.30$ $\mathrm{mm}$ to all trunk sections (the extraction efficiency were $52.87 \pm 1.12 \%, 56.95 \pm 0.70 \%$ and $58.06 \pm 0.47 \%$ for $\mathrm{T}, \mathrm{M}$ and B trunk sections respectively). In addition, there was no significant difference of extraction efficiency between the sections $(\mathrm{P}>0.05)$, showing that the selection of the sago trunk section did not influence the extraction efficiency because the grated sago sizes were the same. Moreover, there were slight differences in extraction efficiency between the grated sizes of $X<0.30 \mathrm{~mm}$ and $0.30 \leq \mathrm{X}<0.45 \mathrm{~mm}(\mathrm{P}<0.05)$. At the grated size of $0.45 \leq \mathrm{X}<0.85 \mathrm{~mm}$, the extraction efficiency began to decrease until the size of $0.85 \leq \mathrm{X}<1.00 \mathrm{~mm}$ and then became constant at $1.00 \leq \mathrm{X}<2.00 \mathrm{~mm}$. Furthermore, the extraction efficiency continued to decrease until $\mathrm{X} \geq 2.80$ $\mathrm{mm}$. This decreasing pattern happened because the embedded native starch in smaller fiber size was easy to be released. On the contrary, there was a slight increase in extraction efficiency between 5 mins and 24-hour steeping period $(\mathrm{P}<0.05)$ with an average percentage difference of $1.80 \pm 1.13 \%$. However, when the steeping period was further increased from 24 to $72 \mathrm{hrs}$, the increment of extraction efficiency was not significant $(\mathrm{P}>0.05)$, meaning that the increase of extraction efficiency with steeping period was stopped at a rate beyond $24 \mathrm{hrs}$. This observation reflected the starch recovery results as stated earlier since the extraction efficiency depended on starch recovery weight, showing a correlation between extraction efficiency and starch recovery.

The total starch recovery is the total weight of sago starch extracted from the grated sago which was a mix of various sizes produced by the grating machine. Figure 8 shows the total starch recovery percentage for T, M and $\mathrm{B}$ trunk sections at different steeping periods. The result 
Table 2. Chemical determination of TSC according to trunk sections and extraction efficiency according to grated sizes at different steeping periods

\begin{tabular}{|c|c|c|c|c|c|c|c|c|c|c|}
\hline \multirow{3}{*}{ 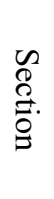 } & \multirow{3}{*}{$\begin{array}{c}\text { Total } \\
\text { starch } \\
\text { content } \\
(\%)\end{array}$} & \multirow{3}{*}{$\begin{array}{l}\text { Grated sago } \\
\text { size }\end{array}$} & \multicolumn{8}{|c|}{ Steeping period } \\
\hline & & & \multicolumn{2}{|c|}{$5 \mathrm{~min}$} & \multicolumn{2}{|c|}{24 hours } & \multicolumn{2}{|c|}{48 hours } & \multicolumn{2}{|c|}{72 hours } \\
\hline & & & $\begin{array}{c}\text { Starch } \\
\text { recovery } \\
(\%)\end{array}$ & $\begin{array}{c}\text { Efficiency } \\
(\%)\end{array}$ & $\begin{array}{c}\text { Starch } \\
\text { recovery } \\
(\%)\end{array}$ & $\begin{array}{c}\text { Efficiency } \\
(\%)\end{array}$ & $\begin{array}{c}\text { Starch } \\
\text { recovery } \\
(\%)\end{array}$ & $\begin{array}{c}\text { Efficiency } \\
(\%)\end{array}$ & $\begin{array}{c}\text { Starch } \\
\text { recovery } \\
(\%)\end{array}$ & $\begin{array}{c}\text { Efficiency } \\
(\%)\end{array}$ \\
\hline \multirow{7}{*}{$\overrightarrow{0}$} & \multirow{7}{*}{45.4} & $X<0.3$ & 23.27 & 51.26 & 24.03 & 52.92 & 24.38 & 53.7 & 24.32 & 53.58 \\
\hline & & $0.3 \leq X<0.45$ & 21.71 & 47.83 & 22.52 & 49.61 & 22.53 & 49.63 & 22.74 & 50.1 \\
\hline & & $0.45 \leq X<0.85$ & 19.59 & 43.15 & 19.08 & 42.03 & 19 & 41.86 & 19.19 & 42.27 \\
\hline & & $0.85 \leq \mathrm{X}<1$ & 18.94 & 41.71 & 18.94 & 41.71 & 19.04 & 41.93 & 19.08 & 42.03 \\
\hline & & $1 \leq \mathrm{X}<2$ & 18.26 & 40.23 & 18.47 & 40.69 & 18.79 & 41.4 & 18.65 & 41.08 \\
\hline & & $2 \leq X<2.8$ & 17.61 & 38.79 & 18.25 & 40.2 & 18.32 & 40.35 & 18.41 & 40.54 \\
\hline & & $\mathrm{X} \geq 2.8$ & 17.05 & 37.55 & 17.42 & 38.38 & 17.5 & 38.55 & 17.42 & 38.38 \\
\hline \multirow{7}{*}{$\frac{3}{\frac{2}{2}}$} & \multirow{7}{*}{39.83} & $X<0.3$ & 22.46 & 56.37 & 23.08 & 57.93 & 22.69 & 56.96 & 22.52 & 56.54 \\
\hline & & $0.3 \leq X<0.45$ & 19.73 & 49.54 & 20.29 & 50.94 & 19.94 & 50.07 & 19.66 & 49.35 \\
\hline & & $0.45 \leq X<0.85$ & 19.29 & 48.43 & 19.18 & 48.15 & 19.48 & 48.9 & 19.49 & 48.93 \\
\hline & & $0.85 \leq \mathrm{X}<1$ & 18.69 & 46.93 & 18.52 & 46.49 & 18.64 & 46.79 & 18.98 & 47.65 \\
\hline & & $1 \leq \mathrm{X}<2$ & 18.44 & 46.29 & 18.61 & 46.71 & 18.31 & 45.96 & 18.54 & 46.54 \\
\hline & & $2 \leq X<2.8$ & 17.49 & 43.9 & 18.01 & 45.21 & 18.03 & 45.27 & 17.39 & 43.65 \\
\hline & & $X \geq 2.8$ & 16.77 & 42.1 & 16.92 & 42.49 & 17.38 & 43.63 & 16.99 & 42.66 \\
\hline \multirow{7}{*}{$\begin{array}{l}\mathscr{O} \\
\stackrel{\circ}{\circ} \\
\stackrel{\Xi}{\Xi}\end{array}$} & \multirow{7}{*}{38.97} & $X<0.3$ & 22.37 & 57.4 & 22.77 & 58.42 & 22.74 & 58.37 & 22.62 & 58.05 \\
\hline & & $0.3 \leq X<0.45$ & 19.63 & 50.37 & 20.25 & 51.98 & 20.12 & 51.64 & 20.15 & 51.72 \\
\hline & & $0.45 \leq X<0.85$ & 19.28 & 49.48 & 19.45 & 49.91 & 19.65 & 50.42 & 19.67 & 50.47 \\
\hline & & $0.85 \leq \mathrm{X}<1$ & 18.47 & 47.41 & 18.83 & 48.32 & 18.65 & 47.86 & 18.93 & 48.57 \\
\hline & & $1 \leq \mathrm{X}<2$ & 18.45 & 47.35 & 18.62 & 47.78 & 18.46 & 47.38 & 18.53 & 47.55 \\
\hline & & $2 \leq X<2.8$ & 17.6 & 45.17 & 17.64 & 45.28 & 17.8 & 45.68 & 17.46 & 44.8 \\
\hline & & $\mathrm{X} \geq 2.8$ & 16.81 & 43.15 & 17.01 & 43.66 & 17.04 & 43.72 & 17.19 & 44.11 \\
\hline
\end{tabular}

showed that the total starch recovery was not significant $(\mathrm{P}>0.05)$ between the steeping period with average values of $19.86 \pm 0.14 \%, 19.03 \pm 0.08 \%$ and $19.03 \pm 0.11 \%$ for T, M and B sections, respectively. The total starch recovery was higher than obtained by Wan Mohd Fariz et al. (2018) at about $7.73 \%$ to $9.5 \%$. However, it was slightly lower compared to a prior study by Siti Mazlina et al. (2007) (25.76\%). The difference might be due to the wet grading process, causing an increased percentage of ruptured sago trunk structure bonding. Siti Mazlina et al. (2007) noted that the starch granules present in the sago pith were subsequently released when they were ruptured during the grinding process.

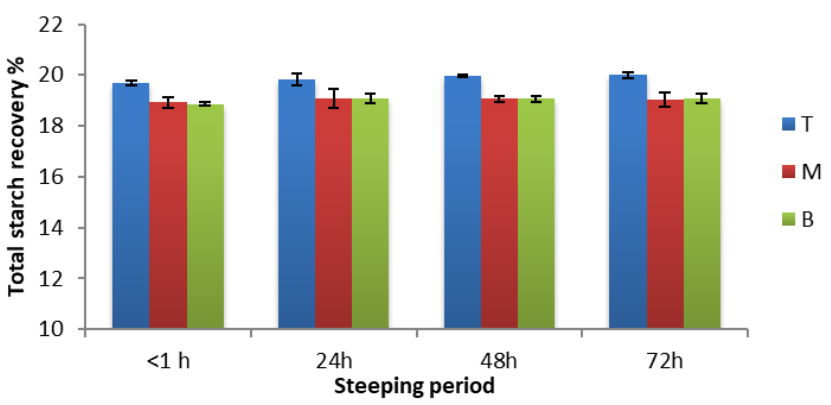

Figure 8 . The starch percentage recovery (\%) produce by grating machine. Error bars were expressed as mean $\pm \mathrm{SD}$; $\mathrm{n}=6$.

For further comparison, several previous studies used wet-base starch as the calculation of starch recovery input value. Therefore, the calculated values of starch recovery using the wet-base as the input values ranged from $24.04 \%$ up to $25.15 \%$ at $\mathrm{MC}$ of $35.80 \pm 0.43 \%$ (starch MC before drying) for the present study. The obtained values were in close agreement with Flach (1997) and Darma et al. (2014) in which the starch recovery ranged from 10 to $25 \%$ and 12.43 to $39.89 \%$, respectively. Furthermore, Darma et al. (2017) reported that their starch recovery ranged from 23 to $27 \%, 15$ to $25 \%, 35.45 \%$ and 43 to $48 \%$, respectively. The variation of starch recovery obtained between the studies might be due to different grated sago sizes and extraction methods. For the present study, the water extraction method was conducted without repetition to ensure optimal usage of water. Basically, the conventional sago extraction method consumed high amounts of water due to the repetition of adding water to grated sago (Jong, 1995a). Water was added during the extraction process as a key element to dissolve and release the starch granules from the pith (Kamal et al., 2007).

\section{Conclusion}

The result of the study showed that a substantial amount of starch could be extracted from the grated sago by reducing the grated size to $X<0.30 \mathrm{~mm}$, allowing up to $58 \%$ efficiency of extraction. A smaller size of grated sago facilitates the high release of native starch. 
Independent variables such as grated size affected the starch recovery the most. Furthermore, in order to increase the recovery, it is suggested to increase the steeping period up to $24 \mathrm{hrs}$ but further increment of steeping period is not necessary. The selection of sago trunk also affected the starch recovery, but not the extraction efficiency. Lastly, it is believed that further development in extraction techniques will improve the starch recovery and at the same time minimize the extraction period.

\section{Acknowledgement}

The authors would like to express gratitude for the research financial support by CRAUN Research Sdn Bhd and MARDI (Project code: FS024210). A special appreciation to the team members from MARDI and UPM facilities in providing suggestions, encouragements and coordination to this project.

\section{References}

AACC. (2000). Methods 55-10 and 76-13: International approved methods of analysis. $10^{\text {th }}$ ed. USA: AACC International.

Abd Aziz, S. (2002). Sago starch and its utilization. Journal of Bioscience and Bioengineering, 94(6), 526-529. https://doi.org/10.1016/S1389-1723(02) 80190-6

ASTM. (2001). Standard C136-01: Test method for sieve analysis of fine and coarse aggregates. West Conshohocken, Philadelphia, USA: ASTM International.

Bintoro, M.H. (2011). Progress of Sago Research in Indonesia. Proceeding of the 10th International Sago Symposium, 29-31 October 2011, p. 16-34. Bogor, Indonesia: IPB International Convention Center.

Darma, Wang, X.L. and Kito, K. (2014). Development of sago starch extractor with stirrer rotary blade for improving extraction performance. International Journal of Engineering and Technology (IJET), 6(5), 2472-2481.

Darma., Santos, B. and Reniana (2017). Development of Cylinder Type Sago Rasping Machine Using Pointed Teeth. International Journal of Engineering and Technology, 17(1), 25-31

DOA. (2017). Malaysia industrial crops statistics. Putrajaya, Malaysia: Department of Agriculture.

Flach, M. (1997). Sago palm (Metroxylon sagu Rottb.), Rome: International Plant Genetic Resources Institute (IBPGR).

Hu, D., Liu, X.B., She, H.Z., Gao, Z., Ruan, R.W., Wu, D.Q., Yi, Z.L. (2017). The lignin synthesis related genes and lodging resistance of Fagopyrum esculentum. Biologia Plantarum, 61, 1-9. https:// doi.org/10.1007/s10535-016-0685-4

Jong, F.S. (1995a). Distribution and Variation in the Starch Content of Sago Palms (Metroxylon sagu Rottb.) at Difference Growth Stages. Sago Palm, 3 (2), 45-54.

Jong, F.S. (1995b). Research for the development of sago palm (Metroxylon sagu Rottb.) cultivation in Sarawak, Malaysia. Wageningen, The Netherlands: Wageningen Agriculture Univ, $\mathrm{PhD}$ thesis.

Kamal, S.M.M., Mahmud, S.N., Hussain, S.A. and Ahmadun, F.R. (2007). Improvement on sago flour processing. International Journal of Engineering and Technology, 4(1), 8-14

Kaur, B., Fazilah, A. and Karim, A. (2011). Alcoholicalkaline treatment of sago starch and its effect on physicochemical properties. Food and Bioproducts Processing, 89(4), 463-471. https://doi.org/10.1016/ j.fbp.2010.09.003

Linggang, S., Phang, L.Y., Wasoh, M.H. and Abd Aziz, S. (2012). Sago pith residue as an alternative cheap substrate for fermentable sugars production. Applied Biochemistry and Biotechnology, 167,122-131. https://doi.org/10.1007/s12010-012-9592-0

Mary Anupama, P., Ayyanna, C. and Ramana, T. (2010). Systematic optimization of mashing parameters of pearl millets. Asian Journal of Experimental Biological Sciences, 1(4), 747-750.

Matsuoka, S. (2008). Wood hardness in nest trees of the great spotted woodpecker dendrocopos major. Ornithological Science, 7(1), 59-66. https:// doi.org/10.2326/1347-0558(2008)7[59:WHINTO] 2.0.CO;2

Mistry, A.H., Schmidt, S.J., Eckhoff, S.R. and Sutherland, J.W. (1992). Alkali extraction of starch from corn flour. Starch - Stärke, 44(8), 284-288. https://doi.org/10.1002/star.19920440803

Naim, H.M., Yaakub, A.N., Hamdan, A. and Asmah, D. (2016). Commercialization of sago through estate plantation scheme in Sarawak: The way forward. International Journal of Agronomy, 2016, 8319542. https://doi.org/10.1155/2016/8319542

Oyedeji, O., Young, A. and Fasina, O. (2017). Bending properties of loblolly pine. Industrial Crops and Products, 109, 905- 911. https://doi.org/10.1016/ j.indcrop.2017.09.060

Saengchana, K., Nopharatana, M., Lerdlattaporn, R. and Songkasiri, W. (2015). Enhancement of starch-pulp separation in centrifugal-filtration process: Effects of particle size and variety of cassava root on free starch granule separation. Food and Bioproducts 
Processing, 95, 208-217. https://doi.org/10.1016/ j.fbp.2015.05.008

Siti Mazlina, M.K., Siti Norfadhillah, M., Siti Aslina, H. and Fakrul Razi, A. (2007). Improvement on sago flour processing. International Journal of Engineering and Technology, 4(1), 8-14.

Tay, P.W., H'ng, P.S., Chin, K.L., Wong, L.J. and Luqman, A.C. (2013). Effects of steeping variables and substrate mesh size on starch yield extracted from oil palm trunk. Industrial Crops and Products, 44, 240-245. https://doi.org/10.1016/ j.indcrop.2012.10.034

Wan Mohd Fariz, W.A., Rosnah, S., Azman, H., Mohd Shahrir, A., Saiful Azwan, A., Asnawi, S.H. and Zainun M.S. (2018). Effect of grater position on the size of grated sago (Metroxylon spp.). Food Research, 2(6), 572-577. https://doi.org/10.26656/ fr.2017.2(6).125

Yamada, H., Tanaka, R., Sulaiman, O., Hashim, R., Hamid, Z.A.A., Yahya, M.K.A., Kosugi, A., Arai, T., Murata, Y., Nirasawa, S., Yamamoto, K., Ohara, S., Mohd Yusof, M.N. and Mori, Y. (2010). Old oil palm trunk: A promising source of sugars for bioethanol production. Biomass and Bioenergy, 34 (11), 1608-1613. https://doi.org/10.1016/ j.biombioe.2010.06.011

Yajie, Z., Patrick, G., Yongcan, J. and Huining, X. (2020). Biodegradable polymers and green-based antimicrobial packaging materials: A mini-review. Advanced Industrial and Engineering Polymer Research, 3(1), 27-35. https://doi.org/10.1016/ j.aiepr.2019.11.002

Yamamoto, Y. (2014). Sago as an Approach to Food and Nutritional Security. Global Food Security Forum, 78 July 2014. Kuala Lumpur, Malaysia: Putrajaya Marriott Hotel. 